\title{
Evaluation of new antiemetic agents and definition of antineoplastic agent emetogenicity - state of the art
}

\author{
Steven M. Grunberg • David Warr • Richard J. Gralla • \\ Bernardo L. Rapoport • Paul J. Hesketh • \\ Karin Jordan • Birgitte T. Espersen
}

Received: 20 April 2010 /Accepted: 31 August 2010 /Published online: 24 October 2010

(C) Springer-Verlag 2010

\begin{abstract}
Antiemetic drug development can follow the same logical path as antineoplastic drug development from appropriate preclinical models through Phase I, Phase II, and Phase III testing. However, due to the marked success of antiemetic therapy over the last 25 years, placebo antiemetic treatment against highly or moderately emetogenic chemotherapy is not acceptable. Promising antiemetic agents therefore rapidly reach Phase III testing, where they are substituted into or added to effective and accepted
\end{abstract}

S. M. Grunberg $(\bowtie)$

Division of Hematology/Oncology,

University of Vermont College of Medicine,

89 Beaumont Avenue, Given Building E214,

Burlington, VT 05405, USA

e-mail: Steven.Grunberg@uvm.edu

D. Warr

Princess Margaret Hospital, University of Toronto,

Toronto, Canada

R. J. Gralla

North Shore-LIJ Cancer Institute,

Lake Success, NY, USA

B. L. Rapoport

Medical Oncology Centre of Rosebank,

Johannesburg, South Africa

P. J. Hesketh

St. Elizabeth's Medical Center,

Boston, MA, USA

K. Jordan

University of Halle,

Halle, Germany

B. T. Espersen

Aarhus University Hospital,

Aarhus, Denmark regimens. One challenge of antiemetic drug development is determining whether substitution is indeed acceptable or whether prior regimens must be maintained intact as a basis for further antiemetic drug development. An additional challenge is the classification of emetogenic level of new antineoplastic agents. Accurate reporting of emetogenicity of such antineoplastic agents in the absence of preventive antiemetic treatment may not be available. However, at the 2009 Multinational Association of Supportive Care in Cancer (MASCC)/European Society of Medical Oncology (ESMO) Consensus Conference, an expert panel used best available data to establish rankings of emetogenicity. Oral chemotherapeutic agents are ranked separately from intravenous agents, recognizing intrinsic differences in emetogenicity as well as differing schedules of administration. Since oral chemotherapeutic agents are often administered in extended regimens, the distinction between acute and delayed emesis is less clear, and cumulative emesis must be considered. As control of vomiting has improved, attention has shifted to control of nausea, a related but distinct and equally important problem. Additional efforts will be necessary to understand mechanisms of nausea and to identify optimal remedies.

Keywords Emetogenicity - Nausea · Vomiting ·

Classification

\section{Introduction}

Evaluation of new antiemetic agents follows principles similar to the development of new antineoplastic agents. Preclinical models, such as the ferret [1] and the least shrew [2], with emetic responses similar to those in patients, can be used to identify agents that may have antiemetic 
properties against standard challenge agents and can also be used to characterize the potency and time course of antiemetic activity, placing these agents in perspective to those currently in clinical use. Phase I trials in normal subjects may be employed to characterize toxicity and pharmacokinetic parameters as well as exploring potential drug interactions. However, Phase II and Phase III studies take on an added dimension of complexity since new antiemetic agents are designed to be used against emetic agonists which may be of different potency and have different time-course characteristics themselves. In view of the lack of highly effective salvage therapy for patients with refractory emesis, it would be reasonable to evaluate new agents in this setting, and success of a new single agent in attaining antiemetic protection would indeed be an impressive achievement [8]. However, using these agents against the most difficult emetogenic challenge will not gain a realistic estimate of efficacy in standard first-line use, and other factors, such as anticipatory emesis, will also come into play [14]. Promising antiemetic agents will therefore rapidly move into the Phase III clinical trials setting and are likely to be evaluated as components of combination regimens (Table 1).

New antiemetic agents can be divided into those that are members of known antiemetic families and those that are unique in structure or mechanism of action. In view of the success of antiemetic drug development over the last 30 years, it is seldom advisable to compare a new antiemetic agent against highly or moderately emetogenic chemotherapy to a true placebo. If a new agent is a member of a known antiemetic family, it is likely to be included as a

Table 1 Recommendations on evaluation of new agents

\begin{tabular}{|c|c|}
\hline \multicolumn{2}{|c|}{ 1. Phases I/II trials should always precede Phase III trials } \\
\hline Level of consensus & High \\
\hline Confidence level & High \\
\hline \multicolumn{2}{|c|}{ 2. Phases I/II trials should define minimal fully effective dose } \\
\hline Level of consensus & High \\
\hline Confidence level & High \\
\hline \multicolumn{2}{|c|}{$\begin{array}{l}\text { 3. Phase III trials should employ a double-blind, randomized parallel } \\
\text { design }\end{array}$} \\
\hline Level of consensus & High \\
\hline Confidence level & High \\
\hline \multicolumn{2}{|c|}{ 4. Phase III trials should use best available treatment as comparator } \\
\hline Level of consensus & High \\
\hline Confidence level & High \\
\hline \multicolumn{2}{|c|}{$\begin{array}{l}\text { 5. Placebo comparators are not appropriate for trials against acute or } \\
\text { delayed emesis with chemotherapeutic agents for which there is a } \\
\text { significant emetic risk. }\end{array}$} \\
\hline Level of consensus & High \\
\hline Confidence level & High \\
\hline
\end{tabular}

Source: Adapted from Grunberg et al. [6] replacement for a known agent in a standard regimen, with the new regimen then compared for non-inferiority to the original standard regimen [3]. Although the non-inferiority design will require much larger patient populations, it is preferable to design such a study, with results that can later be evaluated for suggestions of superiority [13], than to design a superiority trial that may prove to be too small to establish the equivalent value of a new agent that could be added to the antiemetic armamentarium.

Identification of a new family of antiemetics allows a different form of Phase III comparison. In these cases, randomization of a standard regimen with or without the new agent (preferably in a randomized double-blind placebo-controlled design) can be used to assess the contribution of the new family to overall antiemetic protection and to characterize this protection as related to the emetogenicity of the challenge agents, the time course of protection, and the unique or additive effects compared to the standard regimen [4]. It should be noted that changes in the standard regimen may require a re-evaluation of these study designs and results. For example, the combination of an NK-1 antagonist with dexamethasone and ondansetron has been found to be superior to dexamethasone and ondansetron alone [7]. However, since recent data has suggested that the efficacy and mechanism of action of palonosetron may differ from that of ondansetron [10], then an NK-1 antagonist combined with dexamethasone and palonosetron cannot be immediately assumed to be superior to dexamethasone and palonosetron and may require further evaluation. In addition, as indicated by the overall Multinational Association of Supportive Care in Cancer (MASCC) guidelines, the relative value of different regimens must also be considered specifically in regard to the emetogenicity of the antiemetic challenge itself. Relative efficacy in the setting of moderately emetogenic chemotherapy, for example, may be similar but not identical to that against highly emetogenic chemotherapy [15].

Classification of emetogenicity of antineoplastic agents has established the framework against which antiemetic efficacy is defined. At the 2004 Perugia Antiemetic Consensus Conference, the previous five-level antiemetic classification was simplified to a four-level classification by combining the previous Level 3 (30-60\% of patients with emesis) and Level 4 (60-90\% of patients with emesis) into a single moderately emetogenic classification (emesis in $30-90 \%$ of patients), since clinical separation of these two classes of patients was found to be extremely difficult [6]. The categories of highly emetogenic (previously Level $5->90 \%$ of patients with emesis), low emetogenic (previously Level $2-10-30 \%$ of patients with emesis), and minimal emetogenic (previously Level $1-<10 \%$ of patients with emesis [clinically, agents considered to be 
Table 2 Emetogenic potential of single intravenous antineoplastic agents

\begin{tabular}{l}
\hline $\begin{array}{l}\text { Degree of emetogenicity } \\
\text { (incidence) }\end{array}$ \\
\hline
\end{tabular}

\begin{tabular}{|c|c|}
\hline \multirow[t]{6}{*}{ High $(>90 \%)$} & Cisplatin \\
\hline & Mechlorethamine \\
\hline & Streptozotocin \\
\hline & Cyclophosphamide $\geq 1500 \mathrm{mg} / \mathrm{m}^{2}$ \\
\hline & Carmustine \\
\hline & Dacarbazine \\
\hline \multirow[t]{14}{*}{ Moderate $(30-90 \%)$} & Oxaliplatin \\
\hline & Cytarabine $>1000 \mathrm{mg} / \mathrm{m}^{2}$ \\
\hline & Carboplatin \\
\hline & Ifosfamide \\
\hline & Cyclophosphamide $<1500 \mathrm{mg} / \mathrm{m}^{2}$ \\
\hline & Doxorubicin \\
\hline & Daunorubicin \\
\hline & Epirubicin \\
\hline & Idarubicin \\
\hline & Irinotecan \\
\hline & Azacitidine \\
\hline & Bendamustine \\
\hline & Clofarabine \\
\hline & Alemtuzumab \\
\hline \multirow[t]{19}{*}{ Low $(10-30 \%)$} & Paclitaxel \\
\hline & Docetaxel \\
\hline & Mitoxantrone \\
\hline & Doxorubicin $\mathrm{HCl}$ liposome injection \\
\hline & Ixabepilone \\
\hline & Topotecan \\
\hline & Etoposide \\
\hline & Pemetrexed \\
\hline & Methotrexate \\
\hline & Mitomycin \\
\hline & Gemcitabine \\
\hline & Cytarabine $\leq 1000 \mathrm{mg} / \mathrm{m}^{2}$ \\
\hline & 5-Fluorouracil \\
\hline & Temsirolimus \\
\hline & Bortezomib \\
\hline & Cetuximab \\
\hline & Trastuzumab \\
\hline & Panitumumab \\
\hline & Catumaxumab \\
\hline \multirow[t]{8}{*}{ Minimal (<10\%) } & Bleomycin \\
\hline & Busulfan \\
\hline & 2-Chlorodeoxyadenosine \\
\hline & Fludarabine \\
\hline & Vinblastine \\
\hline & Vincristine \\
\hline & Vinorelbine \\
\hline & Bevacizumab \\
\hline
\end{tabular}

Table 3 Emetogenic potential of single oral antineoplastic agents

\begin{tabular}{ll}
\hline Degree of emetogenicity (incidence) & Agent \\
\hline High $(>90 \%)$ & Hexamethylmelamine \\
Moderate $(30-90 \%)$ & Procarbazine \\
Cyclophosphamide & Temozolomide \\
& Vinorelbine \\
Low $(10-30 \%)$ & Catinib \\
& Tegafur uracil \\
& Fludarabine \\
Etoposide \\
Sunitinib \\
Everolimus \\
Lapatinib \\
Lenalidomide \\
Thalidomide \\
Chlorambucil \\
Hinimal $(<10 \%)$ & L-Phenylalanine mustard \\
& 6 -Thioguanine \\
& Methotrexate \\
Gefitinib \\
Erlotinib \\
Sorafenib \\
\end{tabular}

non-emetogenic]) were left intact. However, this resulted in a wide range of stimuli gathered under the single heading of moderately emetogenic chemotherapy. At the 2009 Consensus Conference, this classification was left intact as was the basic principle that the emetogenic classification scheme should be used to describe single agents, since the potential variety of combination doses and schedules of even a few chemotherapeutic agents might defy meaningful classification. However, it was recognized that the commonly used combination of the moderately emetogenic agents cyclophosphamide and doxorubicin that forms the basis of many breast cancer regimens did appear to create a particularly potent moderately emetogenic combination that commonly served as the basis for antiemetic clinical trials and that might require more aggressive antiemetic regimens.

Table 4 Remaining challenges in antiemetic therapy

1. Characterization and prevention of nausea

2. Characterization and management of emetogenicity of oral regimens

3. Determination of intrinsic emetogenicity of new agents

4. Identification of additional relevant neurotransmitter receptors 
As new antineoplastic agents have been developed, we have attempted to add them to the emetogenic classification schema. Such efforts continue to be hampered by the limited recording of "common" toxicities, such as emesis, during antineoplastic drug development, and the unregulated use of prophylactic antiemetics during antineoplastic drug development even before emetogenicity of the agents has been specifically established. Classification of new agents must therefore depend to a certain extent on expert opinion and on synthesis of various limited data sources, still allowing significant consensus but limiting confidence to that allowed by the quality of the underlying data. The accompanying tables represent the present emetogenic classification of commonly used antineoplastic agents. Numerous new agents have been added since 2004, and some agents have been reclassified based on additional data (Table 2).

As recognized at the 2004 Consensus Conference, the increasing use of oral agents (both cytotoxic agents and biologic agents) has created an additional challenge, since such agents tend to be used in extended regimens of daily oral use rather than the single bolus administration commonly seen with intravenous agents. Whether emetogenicity of such agents should be defined based on the acute emetogenicity of a single dose or the cumulative emetogenicity of a full course of chronic administration remains an issue for discussion. This is particularly critical since some of the newer agents may only become consistently emetogenic after a week or more of continuous administration, so that evaluation of only a single day would greatly underestimate the clinical concern. In general, emetogenic classification has therefore been established based on that of a full course of therapy as clinically employed (Table 3). Chronic oral administration also erases the distinction between acute and delayed emesis so that definitions for oral agents must intrinsically differ from those of intravenous agents.

Control of acute vomiting allowed the identification of delayed vomiting as a separate entity. Control of both acute and delayed vomiting has now led to the realization that nausea may be the greatest remaining emetogenic challenge [11]. Although vomiting and nausea seem to appear and respond in parallel, they are not the same phenomena. While vomiting can be objectively measured in terms of number of emetic episodes, nausea is a subjective phenomenon that requires different measurement tools and definitions. It must also be recognized that the standard primary endpoint for emetogenic trials, Complete Response, is defined as "no vomiting and no use of rescue medication" and does not specifically refer to nausea or protection from nausea at all. Certain populations, such as young women being treated for breast cancer, have been identified as being particularly susceptible to nausea out of proportion to the appearance of vomiting [5]. Preliminary clinical trials of several agents have also suggested that just as some agents may be more effective against acute vomiting and some against delayed vomiting, other agents may be more effective against nausea than against vomiting and vice versa $[9,12]$. Identification and characterization of antinausea agents and rational inclusion of these agents into antiemetic regimens may be the primary challenge in coming years (Table 4). Characterization of the nausea phenomenon and its relationship not only to vomiting but also to anorexia and cachexia will lead to greater insights and improved control of these various gastrointestinal toxicities.

Acknowledgement The 2009 MASCC/European Society of Medical Oncology (ESMO) Antiemetic Guideline Update Consensus Meeting was funded by unrestricted grants from Eisai Inc, GlaxoSmithKline, Helsinn Healthcare SA, Merck \& Co. Inc., and Prostrakan Group. These sources had no role in the design, conduct, or results of the conference nor in the preparation of data or this manuscript. Additionally, funding was received from the ESMO and the MASCC. MASCC organized the meeting. Individual members of either or both these organizations participated in the meeting and preparation of the manuscript.

Conflicts of Interest The following authors either received research funding and honoraria or have been a consultant to or an expert witness for:

- Grunberg: GSK, Helsinn, Merck, Eisai, Prostrakan

- Warr: GSK. Merck

- Gralla: GSK, Helsinn, Merck, Eisai

- Rapoport: Merck

- Hesketh: GSK, Merck, Eisai

- Jordan: GSK, Helsinn, Merck

- Espersen: No conflicts reported

\section{References}

1. Ball RS (2006) Issues to consider for preparing ferrets as research subjects in the laboratory. ILAR J 47:348-357

2. Darmani NA, Wang Y, Abad J, Ray AP, Thrush GR, Ramirez J (2008) Utilization of the least shrew as a rapid and selective screening model for the antiemetic potential and brain penetration of substance $P$ and NK1 receptor antagonists. Brain Res 1214:58-72

3. Eisenberg P, Figueroa-Vadillo J, Zamora R, Charu V, Hajdenberg J, Cartmell A, Macciocchi A, Grunberg S, 99-04 Palonosetron Study Group (2003) Improved prevention of moderately emetogenic chemotherapy-induced nausea and vomiting with palonosetron, a pharmacologically novel 5-HT3 receptor antagonist: results of a Phase III, single-dose trial versus dolasetron. Cancer 98:2473-2482

4. Gralla RJ, de Wit R, Herrstedt J, Carides AD, Ianus J, Guoguang-Ma J, Evans JK, Horgan KJ (2005) Antiemetic efficacy of the neurokinin-1 antagonist, aprepitant, plus a 5HT3 antagonist and a corticosteroid in patients receiving anthracyclines or cyclophosphamide in addition to high-dose cisplatin: analysis of combined data from two Phase III randomized clinical trials. Cancer 104:864-868

5. Grunberg SM, Deuson RR, Mavros P, Geling O, Hansen M, Cruciani G, Daniele B, De Pouvourville G, Rubenstein EB, Daugaard G (2004) Incidence of chemotherapy-induced nausea and emesis after modern antiemetics. Cancer 100:2261-2268 
6. Grunberg SM, Osoba D, Hesketh PJ, Gralla RJ, Borjeson S, Rapoport BL, du Bois A, Tonato M (2005) Evaluation of new antiemetic agents and definition of antineoplastic agent emetogenicity - an update. Support Care Cancer 13:80-84

7. Hesketh PJ, Grunberg SM, Gralla RJ, Warr DB, Roila F, de Wit R, Chawla SP, Carides AD, Ianus J, Elmer ME, Evans JK, Beck K, Reines S, Horgan KJ (2003) The oral neurokinin-1 antagonist aprepitant for the prevention of chemotherapyinduced nausea and vomiting: a multinational, randomized, double-blind, placebo-controlled trial in patients receiving high-dose cisplatin - the Aprepitant Protocol 052 Study Group. J Clin Oncol 21:4112-4119

8. Kris MG, Radford JE, Pizzo BA, Inabinet R, Hesketh A, Hesketh PJ (1997) Use of an NK1 receptor antagonist to prevent delayed emesis after cisplatin. J Natl Cancer Inst 89:817-818

9. Meiri E, Jhangiani H, Vredenburgh JJ, Barbato LM, Carter FJ, Yan HM, Baranowski V (2007) Efficacy of dronabinol alone and in combination with ondansetron versus ondansetron alone for delayed chemotherapy-induced nausea and vomiting. Curr Med Res Opin 23:533-543

10. Rojas C, Stathis M, Thomas AG, Massuda EB, Alt J, Zhang J, Rubenstein E, Sebastiani S, Cantoreggi S, Snyder SH, Slusher B (2008) Palonosetron exhibits unique molecular interactions with the 5-HT3 receptor. Anesth Analg 107:469-478
11. Roscoe JA, Morrow GR, Colagiuri B, Heckler CE, Pudio BD, Colman L, Hoelzer K, Jacobs A (2010) Insight in the prediction of chemotherapy-induced nausea. Support Care Cancer 18:869-876

12. Ryan JL, Heckler C, Dakhil SR, Kirshner J, Flynn PJ, Hickok JT, Morrow GR (2009) Ginger for chemotherapy-related nausea in cancer patients: a URCC CCOP randomized, double-blind, placebo-controlled clinical trial of 644 cancer patients. J Clin Oncol 27:15s (suppl; abstr 9511)

13. Saito M, Aogi K, Sekine I, Yoshizawa H, Yanagita Y, Sakai H, Inoue K, Kitagawa C, Ogura T, Mitsuhashi S (2009) Palonosetron plus dexamethasone versus granisetron plus dexamethasone for prevention of nausea and vomiting during chemotherapy: a double-blind, double-dummy, randomized, comparative Phase III trial. Lancet Oncol 10:115-124

14. Stockhorst U, Enck P, Klosterhalfen S (2007) Role of classical conditioning in learning gastrointestinal symptoms. World J Gastroenterol 13:3430-3437

15. Warr DG, Hesketh PJ, Gralla RJ, Muss HB, Herrstedt J, Eisenberg PD, Raftopoulos H, Grunberg SM, Gabriel M, Rodgers A, Bohidar N, Klinger G, Hustad CM, Horgan KJ, Skobieranda F (2005) Efficacy and tolerability of aprepitant for the prevention of chemotherapy-induced nausea and vomiting in patients with breast cancer after moderately emetogenic chemotherapy. J Clin Oncol 23:2822-2830 